\title{
Greenland Clouds Observed in CALIPSO-GOCCP: Comparison with Ground-Based Summit Observations $\mathscr{0}$
}

\author{
Adrien lacour, ${ }^{a}$ Helene Chepfer,${ }^{a}$ Matthew D. Shupe,${ }^{b, c}$ NAThaniel B. Miller,${ }^{b, c}$ \\ VINCENT NOEL, ${ }^{\mathrm{d}}$ JENNIFER KAY, ${ }^{\mathrm{b}, \mathrm{e}}$ DAVID D. TURNER, ${ }^{\mathrm{c}}$ AND RODRIGO GUZMAN ${ }^{\mathrm{f}}$ \\ ${ }^{a}$ Université Pierre et Marie Curie, Laboratoire de Météorologie Dynamique, Institut Pierre Simon Laplace École \\ Polytechnique, Palaiseau, France \\ ${ }^{\mathrm{b}}$ Cooperative Institute for Research in Environmental Sciences, University of Colorado, Boulder, Colorado \\ ${ }^{\mathrm{c}}$ NOAA Earth System Research Laboratory, Boulder, Colorado \\ ${ }^{\mathrm{d}}$ CNRS/INSU, Laboratoire d'Aérologie, Toulouse, France \\ ${ }^{\mathrm{e}}$ Department of Atmospheric and Oceanic Sciences, University of Colorado, Boulder, Colorado \\ ${ }^{\mathrm{f}}$ CNRS, Laboratoire de Météorologie Dynamique, Institut Pierre Simon Laplace Ecole Polytechnique, Palaiseau, France
}

(Manuscript received 27 July 2016, in final form 27 March 2017)

\begin{abstract}
Spaceborne lidar observations from the Cloud-Aerosol Lidar and Infrared Pathfinder Satellite Observations (CALIPSO) satellite provide the first-ever observations of cloud vertical structure and phase over the entire Greenland Ice Sheet. This study leverages CALIPSO observations over Greenland to pursue two investigations. First, the GCM-Oriented CALIPSO Cloud Product (CALIPSO-GOCCP) observations are compared with collocated ground-based radar and lidar observations at Summit, Greenland. The liquid cloud cover agrees well between the spaceborne and ground-based observations. In contrast, ground-satellite differences reach $30 \%$ in total cloud cover and $40 \%$ in cloud fraction below $2 \mathrm{~km}$ above ground level, due to optically very thin ice clouds (IWC $<2.5 \times 10^{-3} \mathrm{~g} \mathrm{~m}^{-3}$ ) missed by CALIPSO-GOCCP. Those results are compared with satellite cloud climatologies from the GEWEX cloud assessment. Most passive sensors detect fewer clouds than CALIPSO-GOCCP and the Summit ground observations, due to different detection methods. Second, the distribution of clouds over the Greenland is analyzed using CALIPSO-GOCCP. Central Greenland is the cloudiest area in summer, at $+7 \%$ and $+4 \%$ above the Greenland-wide average for total and liquid cloud cover, respectively. Southern Greenland contains free-tropospheric thin ice clouds in all seasons and liquid clouds in summer. In northern Greenland, fewer ice clouds are detected than in other areas, but the liquid cloud cover seasonal cycle in that region drives the total Greenland cloud annual variability with a maximum in summer. In 2010 and 2012, large ice-sheet melting events have a positive liquid cloud cover anomaly (from $+1 \%$ to $+2 \%$ ). In contrast, fewer clouds $(-7 \%)$ are observed during low ice-sheet melt years (e.g., 2009).
\end{abstract}

\section{Introduction}

Clouds over Greenland influence the surface energy budget through their impacts on longwave (LW) and shortwave (SW) radiation. While the surface cloud radiative forcing (CRF) depends on cloud properties, surface albedo, and solar zenith angle, cloud LW warming outweighs the SW cooling most of the time.

Supplemental information related to this paper is available at the Journals Online website: http://dx.doi.org/10.1175/ JCLI-D-16-0552.s1.

Corresponding author: Adrien Lacour, adrien.lacour@lmd. polytechnique.fr
As a consequence, clouds warm the Greenland surface throughout the year except in summer over low albedo areas (Cawkwell and Bamber 2002). In this environment, both liquid and ice clouds have a warming effect (Van Tricht et al. 2016). Liquid clouds have a maximum effect in summer when they are the most frequent, whereas ice clouds are present year-round (Miller et al. 2015). The influence of clouds on radiative fluxes is largely driven by their depth or condensed mass (Cawkwell and Bamber 2002), such as the liquid water path for liquid clouds. For instance, Bennartz et al. (2013) showed that thin liquid clouds (with liquid water path between 10 and $40 \mathrm{~g} \mathrm{~m}^{-2}$ ) contributed to melt the Greenland surface by maximizing the positive CRF at the surface during the July 2012 melt event. Since 
Greenland melting contributes to sea level rise (Church et al. 2013), and freshwater discharge (Fichefet et al. 2003 ) to the ocean might induce change in local and global climate, such observations motivate investigations into cloud physical properties and geographic and vertical distributions.

Given the challenges of making observations in the cold dark Arctic, our knowledge about Arctic clouds is limited. Ground-based observing stations face extreme cold weather and ground sensors have to be designed to endure harsh conditions. Ground- and ship-based studies have provided useful Arctic cloud observations (Intrieri et al. 2002; Shupe et al. 2006, 2011). From space, the satellite observations that provide extensive spatial coverage rely primarily on passive detection (Wang and Key 2005). Passive instruments use reflected solar radiation or emitted terrestrial radiation for cloud detection, which compromises the accuracy of cloud detection over iced or snow-covered surfaces (Liu et al. 2010; Stubenrauch et al. 2012). Available since 2006, active remote sensing observations from spaceborne radar and lidar provide the opportunity for a cloud detection that is robustly independent of surface characteristics (Kay and L'Ecuyer 2013; Mioche et al. 2015). Spaceborne lidar observations also provide the opportunity to accurately retrieve cloud phase (Cesana et al. 2016). For example, Cesana et al. (2012) showed that liquid clouds are persistent over the entire Arctic despite temperatures well below $0^{\circ} \mathrm{C}$. The current main limitation of active remote sensing instruments is their spatiotemporal sampling: available active remote sensing observations provide at best seasonal spatial coverage in each year.

Challenging observing conditions limit ground-based cloud observations over Greenland (Griggs and Bamber 2008). Existing results at Summit Station, in central Greenland, showed that clouds are relatively frequent year-round even under cold and dry conditions (Shupe et al. 2013). Clouds detected over that site are typical of the Arctic, including low-level stratiform mixed-phase clouds (Shupe et al. 2011). The presence of clouds in such a cold and dry environment implies that atmospheric conditions and long-range transport support their formation and persistence (Morrison et al. 2012).

In this study, we use observations from the lidar on board the Cloud-Aerosol Lidar and Infrared Pathfinder Satellite Observations (CALIPSO) satellite (Winker et al. 2010) to document cloud cover, vertical structure, and thermodynamic phase over Greenland. CALIPSO provides a unique opportunity to investigate cloud properties over Greenland where spaceborne passive sensors struggle to distinguish bright and cold clouds from the bright and cold surface. Other studies over the Arctic also use the radar on board the CloudSat satellite in complement (Kay and Gettelman 2009; Kay and L'Ecuyer 2013; Blanchard et al. 2014; Mioche et al. 2015). The radar signal can go through atmospheric layers where the lidar is attenuated but suffers from ground contamination due to strong surface return (Marchand et al. 2008). Also, CloudSat cannot document clouds in winter over the Arctic region since November 2011 as the satellite is in day-only operation mode (Nayak et al. 2012).

This work has two objectives. First, we evaluate the GCM-Oriented CALIPSO Cloud Product version 2.9 (CALIPSO-GOCCP; Chepfer et al. 2010; Cesana et al. 2012) over Greenland by comparing the product to ground-based lidar and radar observations (section 3). Second, using the spatial coverage provided by the satellite observations, we characterize cloud distributions and seasonal variability over all of Greenland and investigate if local clouds at Summit Station are representative of the region (section 4). In conjunction with the second objective, we analyze the observed Greenland cloud interannual variability during the period 2008-15 (section 5).

\section{Data and method}

\section{a. Ground-based lidar and radar observations at Summit}

The Integrated Characterization of Energy, Clouds, Atmospheric State, and Precipitation at Summit (ICECAPS) project is designed to study the atmospheric structure and clouds over central Greenland (Shupe et al. 2013). Started during spring 2010, the project will last until at least 2018 and provide an $8+-y r$ data record. The Summit observatory is located at $3215 \mathrm{~m}$ above mean sea level (MSL) at the top of the Greenland Ice Sheet $\left(72.6^{\circ} \mathrm{N}, 38.5^{\circ} \mathrm{W}\right)$. Cloud and atmospheric parameters are measured by remote sensing instruments, complemented by radiosonde measurements twice daily. For the current study, we use measurement from the Millimeter Cloud Radar (MMCR) and MicroPulse Lidar (MPL).

The radar sequentially cycles through four operating modes. Each mode is subject to different sensitivity limitations and operational specifications that characterize most clouds and hydrometeors throughout the troposphere (Moran et al. 1998). Near the surface, the most sensitive mode is able to distinguish reflectivities down to approximately $-60 \mathrm{dBZ}$ from the radar background noise. This sensitivity decreases as a function of height. The results presented here combine the observations from the four modes into a product with a 10-s time resolution and 45-m vertical resolution. A radar range bin is flagged cloudy if the reflectivity is higher than $-30 \mathrm{~dB} Z$. Hereafter, we use a $-30-\mathrm{dB} Z$ cloud 
detection threshold, except when specified. Depending on the ice particle type, the ice water content (IWC) for $-30 \mathrm{dBZ}$ is between $10^{-4}$ and $10^{-3} \mathrm{~g} \mathrm{~m}^{-3}$ for the MMCR (Seo and Liu 2005). Bins with signal-to-noise ratio lower than $-12 \mathrm{~dB} Z$ are rejected. These criteria mean we will miss some clouds with low IWC, although the impact of the cloud detection threshold is examined.

The MPL at Summit has collected backscatter profiles at $532 \mathrm{~nm}$, averaged over $5 \mathrm{~s}$ with $15-\mathrm{m}$ vertical resolution, since June 2010. Wang and Sassen (2001) describe the cloud detection algorithm. The ground lidar is able to detect optically thin cloud layers that the MMCR ground radar may miss (Intrieri et al. 2002). Attenuation of the beam by low-level clouds with optical depth $>\sim 3$ will obscure the atmospheric column and clouds above.

The cloud thermodynamic phase is determined from the linear depolarization ratio $\delta_{L}$ (Sassen 1991) between the power of the backscattered signal in the orthogonal and parallel planes of the linearly polarized source (Flynn et al. 2007). Particles with higher surface complexity will lead to more depolarization of the backscattered signal. Liquid spherical particles generate little depolarization, while ice particles with complex shapes lead to large depolarization. For the MPL at Summit, a cloud is classified as liquid if the temperature is warmer than $-40^{\circ} \mathrm{C}$ (as water does not exist in liquid form at colder temperatures) and if $\delta_{L}<0.07$. This threshold is defined by using the work of Sassen (1991), and takes into account that some aerosol layers are slightly depolarizing in the Arctic (Intrieri et al. 2002). This phase detection does not allow for the coexistence of water and ice in a lidar bin. Temperature profiles are interpolated from twice daily radiosounding measurements taken at 0000 and 1200 UTC.

To avoid the detection of fog, diamond dust, or blowing snow and to account for uncertainties in the lidar overlap zone, the measurements start at $150 \mathrm{~m}$ above ground level (AGL) for both ground radar and lidar. For the ground-based lidar only, the data located above $8 \mathrm{~km}$ AGL are also rejected because at these altitudes the signal-to-noise ratio is low and false detection may occur.

\section{b. Spaceborne lidar observations: CALIPSO- GOCCP}

\section{1) STANDARD GOCCP PRODUCT}

We use the monthly mean cloud cover and cloud fraction profiles from the CALIPSO-GOCCP (Chepfer et al. 2010,2013$)$, gridded at $2^{\circ} \times 2^{\circ}$ with a 480 -m vertical resolution.

In CALIPSO-GOCCP, the cloud detection at each level is based on two altitude resolved values: 1) the scattering ratio (SR) between the observed attenuated backscatter signal (ATB) and the signal that would be observed in clear-sky conditions $\left(\mathrm{ATB}_{\mathrm{mol}}\right)$ and 2$)$ the difference $\Delta \mathrm{ATB}=\mathrm{ATB}-\mathrm{ATB}_{\mathrm{mol}}$. In each profile, a 480-m-thick layer is classified as "cloudy" when SR $>5$ and $\Delta$ ATB $>2.5 \times 10^{-3} \mathrm{~km}^{-1} \mathrm{sr}^{-1}$, "clear" when $0.01<$ SR $<1.2$, "uncertain" when $1.2>$ SR $>5$ (likely aerosols or optically thin clouds), and "fully attenuated" when SR $<0.01$. The fully attenuated category corresponds to altitudes that the laser beam cannot reach because of the high optical thickness of the layers above. The vertical resolution of the SR profile is $480 \mathrm{~m}$, and the horizontal resolution is $330 \mathrm{~m}$ along track and $75 \mathrm{~m}$ across track.

The main limitation of CALIPSO-GOCCP is that it does not detect clouds that are optically very thin (Chepfer et al. 2010, 2013). Based on the lidar equation (detailed in the online supplemental material) we found that, typically, a cloud with a top at $8 \mathrm{~km}$ MSL containing ice crystals of 50- $\mu \mathrm{m}$ radius [as in Shupe et al. (2001)] and SR $>5$ corresponds to an IWC above $2.5 \times 10^{-3} \mathrm{~g} \mathrm{~m}^{-3}$ and an optical depth $\tau$ between 0.05 and 0.3 for a vertical thickness between 1 and $6 \mathrm{~km}$. This means that the standard CALIPSO-GOCCP product will typically miss clouds with $\tau<0.05-0.3$, IWC smaller than $2.5 \times 10^{-3} \mathrm{~g} \mathrm{~m}^{-3}$, or any equivalent combination including larger particle radius $(>50 \mu \mathrm{m})$, lower IWC $\left(<0.003 \mathrm{~g} \mathrm{~m}^{-3}\right)$, or thinner vertical extent (Reverdy et al. 2015). The CALIPSO-GOCCP $480-\mathrm{m}$ vertical resolution can be a limiting factor. With the lidar equation, we evaluated the sensitivity of the cloud detection in relation to the vertical resolution. If the cloud thickness is less than $480 \mathrm{~m}$, the cloud might be undetected if IWC $<10^{-2} \mathrm{~g} \mathrm{~m}^{-3}$. The minimum IWC detectable in CALIPSO-GOCCP is a little larger than the minimum IWC detectable by the ground-based radar MMCR (from $10^{-4}$ to $10^{-3} \mathrm{~g} \mathrm{~m}^{-3}$ ) when the radar cloud detection threshold is set at $-30 \mathrm{~dB} Z$.

In this study, we also used the cloud thermodynamic phase from CALIPSO-GOCCP (Cesana and Chepfer 2013). GOCCP classifies cloud in three categories: ice, liquid, and undefined phase. The latter corresponds to situations where a cloud is detected but the phase cannot be determined with confidence. Typically these are clouds located below other highly reflective clouds $(\mathrm{SR}>30$ ) (Cesana et al. 2016) or clouds that contain ice crystals that are horizontally oriented in space (Hu et al. 2001; Noel and Chepfer 2010; Cesana and Chepfer 2013).

\section{2) MODIFIED CALIPSO-GOCCP PRODUCT}

As the polar land regions contain frequent optically thin ice clouds (Spinhirne et al. 2005) not seen by CALIPSO-GOCCP (Chepfer et al. 2013), we created a 


\section{Night-time case study}


FIG. 1. ATB profiles along orbits sections above Greenland. (a) ATB signal along a nighttime orbit on 20 Dec 2013 with 30-m vertical resolution. (b) ATB profile corresponding to the white line in (a). The ATB profile here is averaged to be $480 \mathrm{~m}$ vertically resolved. (c),(d) As in (a),(b), but with daytime profiles taken 15 May 2013. The blue and red lines in (b),(d) indicate, respectively, the cloud detection threshold used in standard CALIPSO-GOCCP and in CALIPSOGOCCP $_{\text {green. }}$ The gray shading shows the area where clouds are detected in standard CALIPSO-GOCCP. The yellow

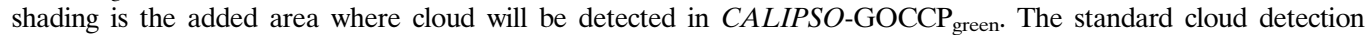
threshold combines 2 conditions: $\mathrm{SR}>5$ and ATB $-\mathrm{ATB}_{\mathrm{mol}}<2.5 \times 10^{-3} \mathrm{~km}^{-1} \mathrm{sr}^{-1}$. For the modified threshold, the conditions to detect a cloud are: $\mathrm{SR}>1.2$ and $\mathrm{ATB}-\mathrm{ATB}_{\mathrm{mol}}<7 \times 10 \mathrm{~km}^{-1} \mathrm{sr}^{-1}$.

modified product CALIPSO-GOCCP green $_{\text {specifically }}$ to investigate the sensitivity of the standard GOCCP product in Greenland (section 3b). CALIPSO$\mathrm{GOCCP}_{\text {green }}$ uses smaller SR and $\triangle \mathrm{ATB}$ thresholds than the standard CALIPSO-GOCCP in order to detect optically thinner clouds: $\mathrm{SR}_{\text {green }}=1.2$ and $\triangle \mathrm{ATB}_{\text {green }}=$ $7 \times 10^{-4} \mathrm{~km}^{-1} \mathrm{sr}^{-1}$. The $\mathrm{SR}_{\text {green }}$ threshold is defined to include the uncertain fraction that corresponds to aerosols and thin clouds (Chepfer et al. 2008). The $\Delta \mathrm{ATB}_{\text {green }}$ threshold is defined to avoid false cloud detections in nighttime profiles only.


tects clouds with IWC as low as $10^{-4} \mathrm{~g} \mathrm{~m}^{-3}$ (assuming a 2-km-thick cloud containing 50- $\mu \mathrm{m}$ particles) and mean $\tau \sim 2 \times 10^{-3}$. This modified version of CALIPSOGOCCP can retrieve ice clouds with equivalent properties to those of MMCR (section 2a). Those clouds detected by CALIPSO-GOCCP green $_{\text {that }}$ are not detected by the standard GOCCP likely include thin ice clouds in the free troposphere.

The effect of changing the cloud detection thresholds in CALIPSO-GOCCP ${ }_{\text {green }}$ can be understood with an example analysis of nighttime and daytime profiles. Figure 1 shows two cases above Greenland where clouds are not detected in the standard CALIPSO-GOCCP. In both examples, the strong signal at $3 \mathrm{~km}$ is the signal backscattered by the surface and is not counted as a cloud. The change from vertical resolution of $60 \mathrm{~m}$ to $30 \mathrm{~m}$ is visible at $8 \mathrm{~km}$ in the ATB profiles along the orbits (Figs. 1a-c).

In the nighttime situation (Fig. 1a), a cloud, probably made of ice (cf. section 4b), is seen between 6 and $7 \mathrm{~km}$ 
MSL. After averaging the profile near $38.7^{\circ} \mathrm{W}$ (arrow) over $480 \mathrm{~m}$, the cloud is undetected using the CALIPSOGOCCP thresholds $\left(\mathrm{SR}>5\right.$ and $\triangle \mathrm{ATB}>2.5 \times 10^{-3}$; the gray area in Fig. 1b). The cloud is detected, however, when the CALIPSO-GOCCP ${ }_{\text {green }}$ thresholds are applied $\left(\mathrm{SR}>1.2\right.$ and $\left.\triangle \mathrm{ATB}>7 \times 10^{-4}\right)$. Here the noisy bins are not identified as clouds.

In the daytime situation (Fig. 1, bottom row), noise contamination is much worse. Thin clouds are seen between the ground and $7 \mathrm{~km}$ (Fig. 1c) but undetected in CALIPSO-GOCCP (Fig. 1d, gray area). Those clouds


but noise pixels lead to likely false detections above $8 \mathrm{~km}$. Thus, CALIPSO-GOCCP ${ }_{\text {green }}$ will reveal optically thin clouds unseen by CALIPSO-GOCCP during nighttime, but will also feature false detections due to solar pollution during daytime.

CALIPSO-GOCCP provides the vertical structure of clouds relative to sea level. Since we are interested in low-level clouds located near the surface over Greenland, which has complex topography, for the current study we display vertical profiles as a function of altitude AGL instead of MSL. We use the GEM TerrainBase (NGDC/NESDIS/NOAA/U.S. Department of Commerce 1995) to shift each profile accordingly.

CALIPSO has collected data since 2006, but in November 2007 the satellite tilt was changed from $0.3^{\circ}$ to $3^{\circ}$ off-nadir. Sensitivity studies (not shown) suggest that tilt change may have affected the lidar signal above highly reflecting regions like Greenland. To have a consistent dataset along the studied period, we use only data collected after November 2007.

For this analysis, we define "the Summit area" for comparing ground-based observations and satellite data as the region where the ice sheet surface is higher than $3 \mathrm{~km}$ MSL. The satellite overpasses this area two times every day, once between 0430 and 0530 UTC and once between 1300 and 1400 UTC (see Fig. S1 in the supplemental material). As shown later, the CALIPSO time sampling at Summit does not significantly affect the results presented in this paper. Over the entire Greenland region, CALIPSO first overpasses start at 0500 UTC and the last orbit passes over Greenland at 1600 UTC with the most frequent annual occurrence at 1500 UTC.

\section{c. Satellite cloud climatologies from the GEWEX cloud assessment database}

To put our results in a broader context and provide a representative reference against which they can be compared, we use the most comprehensive cloud retrievals database derived from spaceborne remote sensing measurements. The Global Energy and Water
Cycle Experiment Cloud Assessment (GEWEX-CA; Stubenrauch et al. 2013) combined 12 cloud products from 5 passive sensors and 1 active sensor (CALIPSO, including the products CALIPSO-GOCCP and CALIPSO-ST), repackaged them using consistent formats and units, and made them available online. ${ }^{1}$ We use the cloud amount $1^{\circ} \times 1^{\circ}$ global monthly maps. Table S1 in the supplemental material sums up the GEWEX datasets used here.

The cloud climatologies available in GEWEX-CA integrate a variety of instruments including the multispectral imagers Pathfinder Atmospheres-Extended (PATMOS-x) and Moderate Resolution Imaging Spectroradiometer (MODIS). MODIS has two cloud products, one from the MODIS Science Team (MODIS-ST) and the other from the MODIS Cloud and the Earth's Radiant Energy System (CERES) Science Team (MODIS-CE). Also included are the Atmospheric Infrared Souder (AIRS), the multiangle imager Polarized and Directionality of Earth's Reflectance (POLDER), and finally the CALIPSO Science Team (CALIPSO-ST) product. GEWEX-CA includes a specific version of CALIPSO-GOCCP, constructed from CALIPSO-GOCCP version 2.1. Here we use a more recent version of $C A L I P S O$-GOCCP product, version 2.9 (Cesana et al. 2016) and version 3.0 (Guzman et al. 2017).

For comparison purposes, we use the morning and afternoon (AM/PM) products (AIRS, CALIPSO-ST) that start from daily values averaging both nighttime (0130 local time at the equator) and daytime (1330 local time at the equator) retrievals, and average those over monthly periods like CALIPSO-GOCCP. When AM/ PM products are not available (MODIS, PATMOS- $x$ ) we average nighttime and daytime monthly products, which average separately nighttime and daytime daily values. In addition to 0130 and 1330 local time, MODISST averages also include measurements made at 1030 and 2230 local time from the Terra satellite. PATMOS-x averages also include measurements made at 0730 and 1930 local time. This means that the MODIS-ST and PATMOS-x average retrievals might be more representative of the complete diurnal cycle than the others (AIRS, MODIS-CE, CALIPSO-ST). For POLDER, because of its visible-only principle of measurement, only daytime retrievals at 1330 local time are available; as a result we expect strong deviations between the POLDER observations and those from the other products.

\footnotetext{
${ }^{1}$ All data were obtained through http://climserv.ipsl.polytechnique. fr/gewexca.
} 


\section{d. Definition of the cloud variables}

For every dataset use in this study, the daily cloud cover $\mathrm{CC}_{\text {tot }}$ is the number of profiles containing clouds $\left(N_{\text {tot,cloud }}\right)$ divided by the total number of profiles occurring on that day $\left(N_{\text {profiles }}\right)$ :

$$
\mathrm{CC}_{\text {tot }}=\frac{N_{\text {tot,cloud }}}{N_{\text {profiles }}} .
$$

Note that our definition of cloud cover is not necessarily consistent with, for instance, the often used ISCCP cloud cover definition, because CALIPSO only samples a small fraction of a scene ( $75-\mathrm{m}$ cross track of the orbit) at a given time.

Then, the liquid cloud cover is computed in two ways. The first one is the absolute liquid cloud cover and follows the definition used by the ground-based observations community (Shupe et al. 2013; Miller et al. 2015). The absolute liquid cloud cover referred to here as $\mathrm{CC}_{\text {liq,abs }}$ is the total number of profile containing at least one liquid cloud divided by the total number of profiles accumulated that day:

$$
\mathrm{CC}_{\text {liq,abs }}=\frac{N_{\text {liq }}}{N_{\text {profiles }}} .
$$

The second definition is the relative liquid cloud cover $\mathrm{CC}_{\text {liq,rel }}$ and comes from the standard CALIPSOGOCCP algorithm (Cesana et al. 2012, 2016; Cesana and Chepfer 2013; Pincus et al. 2012). This definition applies to the ground data gives

$$
\mathrm{CC}_{\text {liq,el }}=\frac{N_{\text {liq }}}{N_{\text {liq }}+N_{\text {ice }}} \times \mathrm{CC}_{\text {tot }}
$$

and satisfies the relationship

$$
\mathrm{CC}_{\text {tot }}=\mathrm{CC}_{\text {liq,rel }}+\mathrm{CC}_{\text {ice,rel }} .
$$

As one profile may contain both ice and liquid clouds, $N_{\text {profiles }}$ is lower than the sum of $N_{\text {liq }}$ and $N_{\text {ice. }}$. The same methodologies are followed to calculate the ice cloud covers $\mathrm{CC}_{\text {ice, abs }}$ and $\mathrm{CC}_{\text {ice,rel }}$.

For CALIPSO-GOCCP the undefined phase fraction has to be accounted for. This means that Eq. (3) becomes

$$
\mathrm{CC}_{\text {liq,el }}=\frac{N_{\text {liq }}}{N_{\text {liq }}+N_{\text {ice }}+N_{\text {undef }}} \times \mathrm{CC}_{\text {tot }}
$$

and Eq. (4) becomes

$$
\mathrm{CC}_{\text {tot }}=\mathrm{CC}_{\text {liq,rel }}+\mathrm{CC}_{\text {ice,rel }}+\mathrm{CC}_{\text {undef,rel }} \text {. }
$$

Note that $\mathrm{CC}_{\text {ice,rel }}$ and $\mathrm{CC}_{\text {undef,rel }}$ can be obtain using Eq. (5). Based on these equations, the relative liquid cloud cover [Eqs. (3) and (5)] will be lower than the absolute liquid cloud cover [Eq. (2)]. We keep the two definitions in this study for comparison with previous ground-based studies at Summit and elsewhere and with other studies using CALIPSO-GOCCP relative liquid cloud cover.

The detailed vertical distribution of the clouds is given by the cloud fraction profiles (CF). They are defined as follows: at each altitude the number of cloudy bins is divided by the total number of profiles accumulated during the day (Miller et al. 2015; Shupe et al. 2013). In CALIPSO-GOCCP, for each 480 -m-thick level, CF is the number of cloudy bins divided by the number of bins with SR $>0.01$. Attenuated bins are not considered in the calculation of the cloud fraction as we cannot determine if the bins contain a cloud or not. Since above Greenland the clouds are usually optically thin (Spinhirne et al. 2005; Shupe et al. 2013), the number of fully attenuated profiles is small (less than $5 \%$ of the profile all year long), so dividing by the total number of profiles observed or dividing only by the number of nonattenuated profiles $(\mathrm{SR}>0.01)$ in a $2^{\circ} \times 2^{\circ}$ grid box during a day lead to similar results (section $2 b$ ). The monthly results are the average over each day for which data have been collected.

\section{Summit clouds: Comparisons between ground- and space-based observations}

\section{a. Cloud cover}

\section{1) ACTIVE SENSORS AT GROUND AND IN SPACE}

We first compare the Summit cloud cover observed over Summit by active sensors from the ground and space. We started by examining the missing data for each instrument. Figure 2 shows gaps in the groundbased radar and lidar data as well as in spaceborne lidar data. CALIPSO collects 10 times fewer profiles in the Summit area than the ground-based observations (not shown here), but its sampling is more stable throughout the years. In contrast to satellite data, the ground-based sampling varies in time due to weather conditions and technical issues. Comparisons between satellite and ground-based data shown hereafter focus on 2013, the year with minimum gaps in ground-based observations (yellow highlight in Fig. 2).

Figure 3 presents the cloud cover annual cycles derived from GOCCP and ground-based instruments at Summit in 2013. In June, ground-based observations exhibit a minimum cloud cover that does not show up in CALIPSO. The 2013 cycle measured by CALIPSO is more cloudy in spring $(+10 \%)$ and less cloudy in January $(-5 \%)$ and 


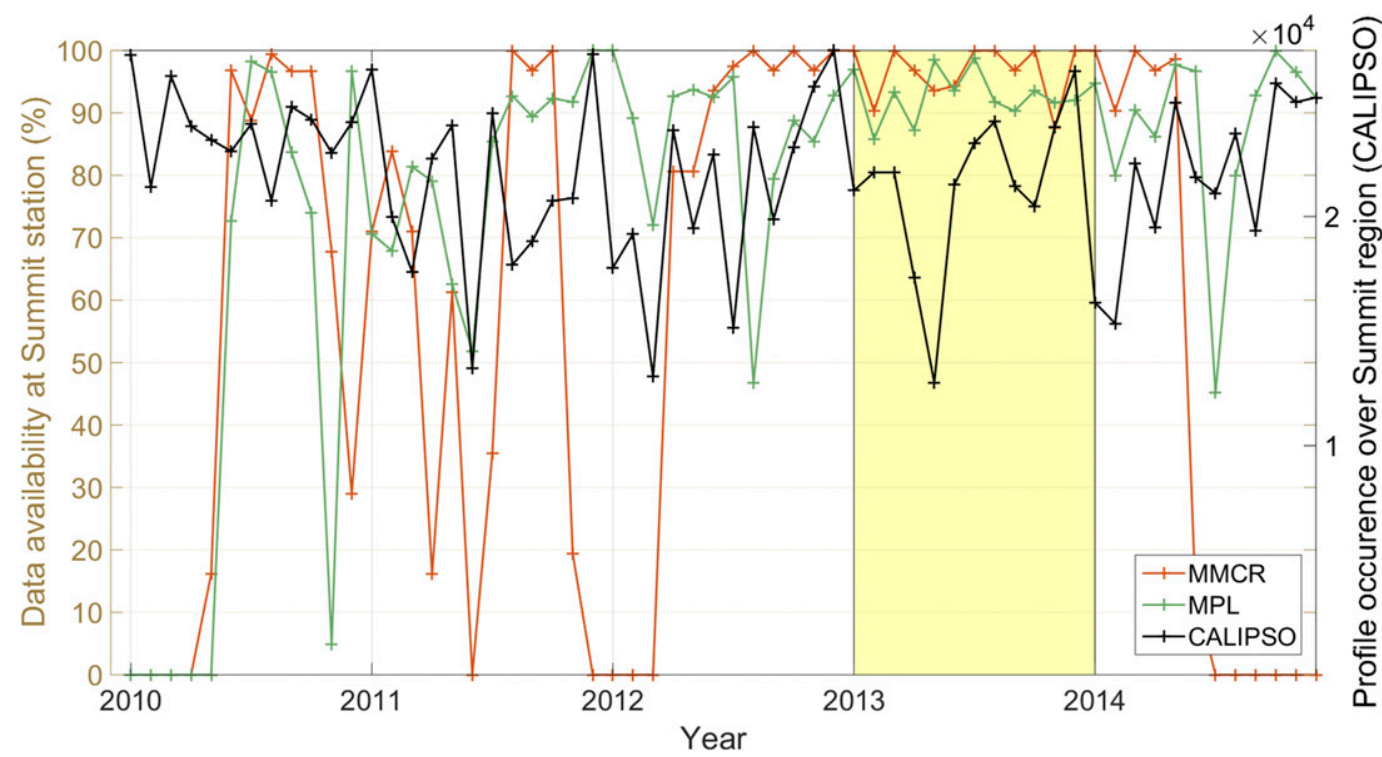

FIG. 2. Availability of the measurements taken by the ground-based radar (MMCR, red) and lidar (MPL, green). Number of profiles collected each year above Summit $(z>3000 \mathrm{~m}$ AGL) by the space lidar (CALIPSO, black). Data availability is the ratio between the number of profiles collected by the instruments and the maximum number of profiles theoretically expected. Year 2013 (yellow) is used for the comparison between the satellite and groundbased active sensors.

October $(-15 \%)$ compared to the average over the 2008 15 period (black dashed line in Fig. 3).

As the ground-based cloud cover is computed using day-long measurements, whereas CALIPSO overpasses the Summit area two times a day (Fig. S1), we also show satellite-ground differences (Fig. 3b) using the ground observations at CALIPSO overpass times between 0530 and 0630 UTC and between 1400 and 1500 UTC. Figure 3b suggests that sampling considerations explain a part of the differences between ground and space observations, but are not their main driver.

Disparities in cloud cover among instruments are related to the measurement technique. Each groundbased instrument has a different perspective on the cloudiness. Depending on the instruments (radar, lidar, ceilometer, etc.) and algorithm used, the detected cloud cover can vary by $20 \%$ (Shupe et al. 2011).

In contrast to the total cloud cover (Fig. 3a), the liquid cloud cover annual cycles observed by the ground-based lidar and CALIPSO-GOCCP for 2013 are generally consistent (Fig. 4). The liquid cloud cover $\mathrm{CC}_{\text {liq,abs }}$ over Summit (Fig. 4a) is at a maximum in July and August (50\%), which is typically 2 months earlier than the maximum found over open water in the Arctic Ocean (e.g., Cesana et al. 2012; English et al. 2014; Shupe 2011). The largest differences between the ground lidar and CALIPSO-GOCCP $(\approx 10 \%)$ occur in October and November. The CALIPSO-GOCCP liquid cloud cover in 2013 appears representative of the average annual cycle over 2008-15 (red dashed line in Fig. 4a). Combining the liquid cloud cover and undefined-phase cloud cover from CALIPSO-GOCCP leads to a larger cloud cover than the ground-based lidar liquid cloud cover in many months. In CALIPSO-GOCCP, Cesana et al. (2016) have found $5.3 \%$ of clouds were undefined-phase during January-March 2010 over the Arctic $\left(60^{\circ}-82^{\circ} \mathrm{N}\right)$ and are likely to be mixed-phase clouds. When the relative cloud cover is used instead of the absolute one [Fig. 4b; Eq. (5)], the liquid cloud cover drops by as much as $20 \%$ in July and August. That difference must be taken into account when looking at Greenland liquid cloud cover results using CALIPSO-GOCCP.

Contrasting the agreement between the liquid cloud cover observed from ground and space (Fig. 4) and the discrepancy between the total cloud cover (Fig. 3a) suggests that the ground and space retrievals primarily disagree on the detection of ice clouds. The ice clouds are optically thinner and thus harder to detect.

\section{2) SATELlite ACTIVE AND PASSIVE SENSORS}

Figure 5 compares the annual mean cloud cover over the Summit area (grid boxes located above $z>3000 \mathrm{~m}$ AGL), from the ground-based observations in 2013 and satellite GEWEX cloud climatologies covering 2008 and 2009 (Table S1). Annual mean cloud cover from MPL and MMCR $(60 \%$ and $68 \%)$ is larger than satellitederived values ( $<60 \%$ ) except for CALIPSO-ST $(71 \%)$ and PATMOS-x $(80 \%)$. Because of their measurement 




b



FIG. 3. Cloud cover annual cycle over Summit from ground-based lidar (MPL, green), radar (MMCR, red), and satellite lidar CALIPSO-GOCCP (black): (a) monthly mean total cloud cover and (b) CALIPSO-GOCCP minus ground-based radar and lidar cloud cover amounts. Dark colors in (b) are for results obtained from cloud cover calculated from all the profiles accumulated in $24 \mathrm{~h}$ each day. The light colors represent the cloud cover amounts calculated from the profiles corresponding to CALIPSO crossing time over the Summit region.

techniques (lidar and IR sounder) and algorithms, these two satellite climatologies are more sensitive than others to optically very thin clouds. The ground-based lidar (MPL) and CALIPSO-GOCCP annual mean cloud covers are consistent. This is probably fortuitous as the MPL detects more clouds in winter and fewer in summer (Fig. 2a).

The difference between CALIPSO-GOCCP and CALIPSO-ST is large $(+10 \%)$ due to differences in cloud detection algorithm and the horizontal averaging behind both datasets (Chepfer et al. 2013). The differences between the annual mean cloud cover obtained by the passive satellite sensors are well explained by the measurement techniques and the sensitivity of each sensor to surface reflection as described in detail in the GEWEX cloud assessment report (Stubenrauch et al. 2012).

Figure 5b shows monthly anomalies in cloud cover, compared to the annual average for each cloud dataset. Most datasets present a primary maximum in cloud cover during summer and a secondary smaller maximum in winter. The time of the summer monthly maximum varies between July and August depending on the climatology. The amplitude of the summer maximum varies between $+10 \%$ and $+22 \%$ relative to the annual mean. In winter, the disagreement between the various climatologies on the amplitude and time of the secondary maximum is larger than in summer because the winter maximum is produced 
a) Absolute liquid cloud cover as defined in Shupe et al. (2013) $\left(C C_{\text {liq, abs }}\right)$



b) Relative liquid cloud cover as defined in standard GOCCPv2.9 algorithm $\left(C C_{\text {liq, rel }}\right)$



FIG. 4. Monthly mean liquid cloud cover for CALIPSO-GOCCP (red) and MPL (green) for (a) the absolute liquid cloud cover definition $\left(\mathrm{CC}_{\text {liq,abs }}=N_{\text {liq }} / N_{\text {profiles }}\right)$ and (b) the relative cloud cover definition $\left[\mathrm{CC}_{\text {liq,rel }}=\right.$ $\left.\left(\mathrm{CC}_{\text {tot }} \times N_{\text {liq }}\right) /\left(N_{\text {liq }}+N_{\text {ice }}\right)\right]$.

by optically thin ice clouds (Shupe et al. 2013), to which instruments are variably sensitive: PATMOS-x algorithms, which are most sensitive to this target, report the largest cloud covers in January.

\section{b. Cloud vertical distribution}

After examining the cloud cover, we now focus on the vertical profile of cloud occurrence. The monthly evolution of the mean cloud fraction profiles retrieved from CALIPSO, MMCR, and MPL is reported in Figs. 6a-c. These figures show significant differences in cloud vertical extent, the amount of low-level clouds, and the seasonal cycles. These differences are likely due to the different sensitivity and viewing geometry of each instrument. The ground-based lidar (Fig. 6c) observes far fewer clouds above $3 \mathrm{~km}$ AGL than the other sensors due to the limited power of its laser (Thorsen et al. 2013; Bennartz et al. 2013; see Fig. S5), which often cannot probe the middle troposphere, especially when optically thick low-level clouds result in the full attenuation of the laser beam. The largest disagreements between the sensors occur in clouds located below $2 \mathrm{~km}$ AGL: the ground-based radar detects more clouds than CALIPSO-GOCCP in all months, sometimes by up to $40 \%$ more. Hereafter, we examine the possible reasons for these differences. 



FIG. 5. Cloud cover over Summit observed from different satellite climatologies as part of the GEWEX cloud assessment. (a) Annual mean cloud cover, where the error whiskers indicate the intra-annual standard deviation and the black dashed line indicates the average cloud cover value in 2013 for CALIPSO-GOCCP. (b) Seasonal cycle normalized to the annual cloud cover.

First, we consider daytime and nighttime independently as the lidar retrievals are sensitive to the background noise coming from solar photons, whereas the radar is not. Figure 6d shows that for CALIPSO-GOCCP the daytime only profiles (May-July) are similar to the nighttime only profiles (November-January). Moreover, the differences between nighttime profiles in CALIPSO-GOCCP and the ground-based radar are still strong, indicating that solar pollution is not the reason for the difference between ground-based radar and spaceborne lidar cloud fraction profiles.

Second, we examine the fully attenuated layer in the lower troposphere (SR $<0.01$ as defined in section 2). Using the detection of surface echo (Guzman et al. 2017), we determined that less than $5 \%$ of profiles do not reach the surface in most months, except in July and August. For these two months, up to $50 \%$ of the profiles do not reach the surface. This is due to the presence of optically thick liquid clouds (Fig. S3) and might explain the cloud fraction differences below $2 \mathrm{~km}$ AGL in summer when they are frequent. However, strong differences between the ground-based radar and $C A L I P S O-G O C C P$ are observed below $2 \mathrm{~km}$ AGL even in winter when the attenuation is not a problem. Solar background and laser attenuation may both contribute to the difference between ground-based radar and lidar measurements as the MPL tends to underestimate the cloud fraction relative to the radar more in summer months.

Third, clouds with vertical extent lower than $480 \mathrm{~m}$ (CALIPSO-GOCCP vertical resolution) and that are optically thin may be missed by CALIPSO-GOCCP: averaging the lidar signal over $480 \mathrm{~m}$ before cloud detection can smooth out signal spikes in such a way that thin clouds may not be detected. We tested the sensitivity of the 



FIG. 6. Vertical cloud profile fraction annual cycle in 2013 over Summit shown as monthly averages observed with (a) CALIPSO-GOCCP, (b) the ground lidar, and (c) the ground radar. (d) Annual mean vertical cloud profile for 2013 (solid lines). The shaded areas are the intra-annual standard deviation. Dashed lines are the average profiles for the months with almost 24-h daylight conditions (May-July), whereas the dashed lines with dots are for the months in nighttime conditions (November-January). The vertical resolution for the space lidar, the ground radar, and the ground lidar, respectively, is $480 \mathrm{~m}, 45 \mathrm{~m}$, and $15 \mathrm{~m}$.

CALIPSO-GOCCP cloud profile to the vertical resolution (as in Chepfer et al. 2010) over the Summit area and found that CALIPSO-GOCCP may miss some 100-500-m-thick ice clouds depending on their altitude. A 500-m-thick cloud below $2 \mathrm{~km}$ AGL is near the detection margin of CALIPSO-GOCCP. From May to September at least $25 \%$ of the clouds have a total thickness below $500 \mathrm{~m}$ and nearly all of them have the cloud base below $2 \mathrm{~km}$ AGL (Shupe et al. 2013). To quantify the effect of vertical resolution on cloud detection, we examined a version of CALIPSOGOCCP with 240-m vertical resolution. Reducing the vertical resolution did not lead to significant changes in the cloud fraction profiles: differences in cloud fraction between the $240-\mathrm{m}$ vertical resolution and $480-\mathrm{m}$ vertical resolution can reach 5\% maximum (not shown here).

Last, we investigate the effect of the cloud detection thresholds in CALIPSO-GOCCP. Imposing a SR $>1.2$ threshold $\left(\mathrm{GOCCP}_{\text {green }}\right.$, yellow profile in Fig. 6d) enhances detection of optically very thin clouds compared to
SR $>5$ in CALIPSO-GOCCP (black profile in Fig. 6d), as discussed in section $2 \mathrm{~b}$, but also includes spurious false positives during daytime, especially at high altitude. The nighttime CALIPSO-GOCCP green $_{\text {cloud fraction profile }}$ matches the nighttime ground-based radar profile below $1 \mathrm{~km}$ AGL. At $4 \mathrm{~km}, C A L I P S O-G O C C P_{\text {green }}$ detects significantly more high-level clouds than GOCCP and more than the ground-based radar and lidar. That difference in nighttime is likely due to the CALIPSO-GOCCP green $_{\text {high }}$ sensitivity to optically thin layers $\left(2 \times 10^{-3}<\tau<0.3\right)$ in the upper troposphere $(4<z<6 \mathrm{~km} \mathrm{AGL})$, which seem frequent over Greenland in the winter. In the supplementary material, a winter case study (Fig. S4) shows optically very thin ice clouds detected by the ground-based radar and lidar being classified as uncertain $(1.2<\mathrm{SR}<5)$ by $C A L I P S O-G O C C P$. In the period used to calculate the nighttime profile (i.e., November-January), the sun is above the horizon only $2 \%$ of the time. As a result, the mean fraction could include some false positives, induced by solar 
noise. This should not significantly change nighttime results. We also examine the impact of different cloud detection thresholds on the ground-based radar results (Fig. 6d; see also Fig. S5). With a cloud detection threshold set to $-45 \mathrm{~dB} Z$, which corresponds to the approximate radar sensitivity at $5 \mathrm{~km}$ (Moran et al. 1998), the radar detects more cloud fraction than CALIPSO-GOCCP green below $4 \mathrm{~km}$ AGL (Fig. 6b, blue profile). At the ground level, the difference of the $-45 \mathrm{dBZ}$ profile is $+22 \%$ in nighttime compared to CALIPSO-GOCCP green $_{\text {and }}+46 \%$ compared to the standard CALIPSO-GOCCP product. For a cloud detection threshold set to $-10 \mathrm{dBZ}$ the radar cloud fraction is consistent with CALIPSO-GOCCP at $1 \mathrm{~km}$ AGL (Fig. S5). The clouds corresponding to radar reflectivities lower than $-10 \mathrm{~dB} Z$ at $1 \mathrm{~km}$ AGL are missed by the standard CALIPSO-GOCCP (SR $>5$ ). Radar reflectivities lower than $-10 \mathrm{~dB} Z$ typically correspond to ice clouds with IWC $<10^{-2} \mathrm{~g} \mathrm{~m}^{-3}$ for all particle sizes (Seo and Liu 2005). As a consequence, clouds with IWC $<10^{-2} \mathrm{~g} \mathrm{~m}^{-3}$ are missed by CALIPSO-GOCCP and represent $35 \%$ of the cloud fraction over Summit in winter. Figure 5 shows that $C A L I P S O-\mathrm{GOCCP}_{\text {green }}(\mathrm{SR}>1.2)$ detects as much clouds below $4 \mathrm{~km}$ AGL as the radar with a detection threshold set at $-30 \mathrm{dBZ}$. This means that CALIPSO$\mathrm{GOCCP}_{\text {green }}$ can detect clouds with IWC $<10^{-4}$ g.m ${ }^{-3}$.

These results suggest that the cloud detection threshold used in the standard CALIPSO-GOCCP is responsible for most of the differences in cloud fraction profile below $4 \mathrm{~km}$ AGL from ground-based instruments. Lowering the cloud


proves the detection of thin ice clouds $(\tau<0.06$ for a $1-\mathrm{km}$ thick cloud), which are probably more frequent in May and September when the differences are the biggest. It also introduces large false-positive cloud detections due to solar noise contamination during daytime. During July and August, the differences between CALIPSO-GOCCP and the ground-based radar are smaller than in winter (Figs. 6a,b) because liquid clouds are more frequent, optically thicker, and easier to detect by both instruments. While changing the cloud detection threshold in CALIPSOGOCCP induces strong change in the cloud fraction profiles, it does not change significantly (less than 5\%) the total cloud cover in nighttime. On the other hand, lowering the ground radar detection threshold (to $-45 \mathrm{dBZ}$ ) increases the total cloud cover especially during winter, suggesting higher occurrence of optically thin clouds during this season compared to the rest of the year (Fig. S5c).

\section{Geographic and seasonal variations in Greenland clouds}

Having confronted CALIPSO-GOCCP compared to datasets over Summit, we now analyze the cloud cover and cloud fraction profiles retrieved from the standard CALIPSO-GOCCP product over the entire Greenland subcontinent, as well as their interannual variability during the 2006-15 time period.

\section{a. Cloud cover}

We divide Greenland into three areas (Fig. 7, top left) depending on their exposure to large-scale atmospheric circulation patterns:

1) Southern Greenland (south of $72^{\circ} \mathrm{N}$ ) is under the North Atlantic influence year-round and includes the Saddle station.

2) Northern Greenland (north of $72^{\circ} \mathrm{N}$ ) is exposed to colder and drier conditions most of the year as the sea around the north coast is typically covered by sea ice except at the end of summer. This region includes the NEEM station.

3) The Summit region $(z>3 \mathrm{~km} \mathrm{MSL})$ has been studied in the previous section.

The annual cycle of cloud cover (Fig. 7a) differs significantly between the southern area and the others. The southern cloud cover is relatively constant and cloudy (65\%) year-round, whereas cloud cover in the northern area exhibits a marked seasonal cycle with a minimum in winter-spring ( $40 \%$ in March) and a maximum in summer (65\% in August). Summit follows the same basic cycle as the northern region, but with $5 \%-10 \%$ more clouds in some months.

Like the total cloud cover, the mean relative liquid cloud cover seasonal cycle (Figs. 7b,c) is very similar between north and Summit regions, with a maximum in July or August and minimum values from December to April. While the Summit liquid cloud cover is close to the Greenland average in winter, it exceeds all other regions in July and August. Consequently, the higher summer liquid cloud cover is observable in the small north region around the NEEM ground station as well (Figs. 7b,c). The liquid cloud cover annual cycle in the southern region has less annual variability than the rest of Greenland, with more liquid clouds in spring than over the northern and Summit regions, and slightly less cloud cover in summer. As observed in Fig. 4, when computed using Eq. (2), the summer liquid cloud cover is higher but the seasonal cycle and relative magnitude remain qualitatively the same (Fig. 7c).

In addition to the liquid cloud cover, we report the ice (Figs. 7d,e) and the undefined (Figs. 7f,g) cloud cover. The ice cloud cover is highest in the south year round and decreases northward. In summer, the ice cloud cover slightly decreases over all of Greenland. Finally, the undefined cloud cover has an annual variability similar to the liquid cloud cover. This cover is relatively 



FIG. 7. Comparison between the cloud cover annual cycle over all of Greenland and northern Greenland, southern Greenland, and Summit area total cloud cover and liquid cloud cover. (left) Results computed over large areas (definition 1) and (right) results from smaller areas (definition 2). Cloud cover amounts are derived from CALIPSO-GOCCP over the period 2008-15. 



FIG. 8. (a) Seasonal variation of the cloud fraction profile derived from CALIPSO-GOCCP between 2008 and 2015 over all Greenland, and the seasonal comparison among northern Greenland, southern Greenland, Summit, and all of Greenland in (b) DJF, (c) MAM, (d) JJA, and (e) SON.

constant in the southern region and has more variability in the northern and Summit region. This means that the increase in liquid and undefined cloud cover in summer in the north and at Summit is responsible for the total cloud cover differences between these two regions and the south.

Since the Summit domain is 10 times smaller than the other two $\left(\approx 10^{6} \mathrm{~km}^{2}\right.$ vs $\left.\approx 10^{5} \mathrm{~km}^{2}\right)$, we examine the sensitivity to area by examining equal area domains (Fig. S2). Results based on these two domain definitions are not appreciably different comparing Fig. 7 against Fig. S2. Hence to accumulate the maximum available profiles and reduce the statistical noise, the zone definition 1 with large northern and southern areas is used for the rest of the study.

\section{b. Cloud vertical distribution}

The total cloud fraction profile over Greenland (Fig. 8a) is around $10 \%$ from 0 to $6 \mathrm{~km}$ AGL. More clouds (+2\%) occur in summer below $4 \mathrm{~km}$ AGL, whereas in winter more clouds occur at high altitude ( $>4 \mathrm{~km} \mathrm{AGL)}$ and fewer at low altitude $(<4 \mathrm{~km}$ AGL) compared to the annual mean.

The southern amount fractions (Figs. 8b-d, red profiles) are constant near the surface ( $\mathrm{CF}=10 \%)$, and they are larger in the free troposphere in all seasons, particularly at $5 \mathrm{~km}$ AGL $(+3 \%)$. We do not expect the numerous clouds above $5 \mathrm{~km}$ AGL to mask the clouds below unless they are too thin. In DJF, for instance, fewer than $5 \%$ of the profiles are fully attenuated at the ground (section 3b). This indicates that free-tropospheric ice clouds occur in the southern region year-round, and that they are responsible for the weak annual cycle in cloud cover observed in southern Greenland (Fig. 7a). In the north, the occurrence of high-level clouds ( $>5 \mathrm{~km}$ AGL) is similar to the occurrence of low-level clouds (Fig. 8).

Figure 8 also indicates how cloud fraction profiles over Summit are uniquely distributed relative to mean cloud fraction profile over Greenland. In the lower troposphere $(z<1 \mathrm{~km} \mathrm{AGL})$, Summit is significantly cloudier than the other two regions in all seasons. The Summit low-level cloud surplus is particularly marked in DJF (Fig. 8b) and JJA (Fig. 8d), when clouds at Summit are at least twice as frequent as over the two other regions. From June to November, these Summit low-level clouds are largely, but not exclusively, liquid $(60.4 \%$ of the detected clouds in JJA and 52.5\% in SON; Fig. S8). In DJF, most of the low-level clouds are composed of ice but the frequency of liquid clouds is relatively high at Summit (35.5\% of the detected clouds).

In the upper troposphere ( $>5 \mathrm{~km}$ AGL), Summit is less cloudy than the rest of Greenland. However, this appears to be due to surface elevation. Plotting the cloud fraction relative to mean sea level instead of ground level (not shown) indicates that the free-tropospheric clouds over Summit are similar to those over the southern region with a maximum of occurrence at $7.5 \mathrm{~km}$ MSL.

In summary, the low-level liquid cloud seasonal cycle is similar in northern and southern Greenland, with a maximum in JJA (not in SON like much of the Arctic). Optically thin free-tropospheric ice clouds are frequent over the south and Summit year-round, but are less frequent over northern Greenland where the atmosphere is drier (Shupe et al. 2013). Summit is cloudier at low levels than the rest of Greenland year-round. 
a) CALIPSO total cloud cover $(57 \%)$
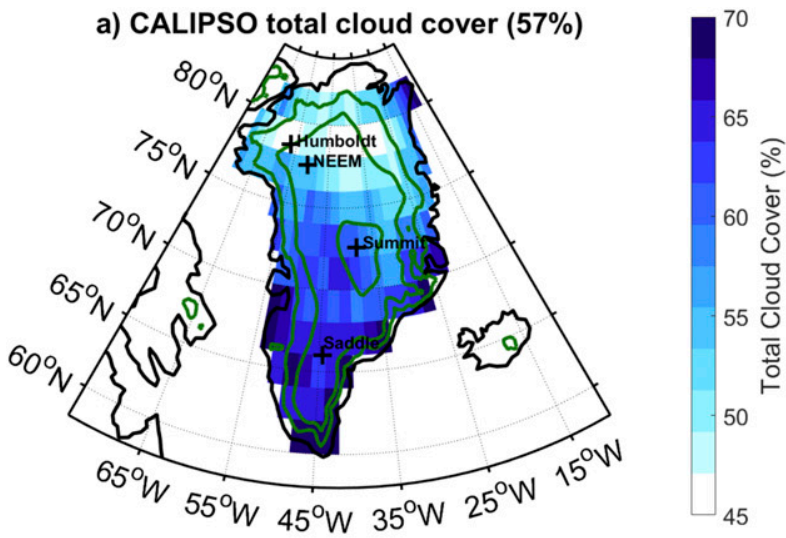

b) CALIPSO absolute liquid cloud cover $(26 \%)$


c) CALIPSO relative liquid cloud cover $(18 \%)$



northern and southern Greenland (Fig. 9a): northern Greenland is less cloudy (53\%) than southern Greenland (64\%). Since the formation of liquid low-level clouds is more influenced, relative to high-level clouds, by smallerscale processes like orography and the proximity to moisture sources, the liquid cloud cover (Figs. 9b,c) exhibits a more complex pattern than the total cloud cover. Liquid clouds are mostly located along the coasts and in the middle of western Greenland between the Summit and NEEM stations, a pattern that is consistent for both liquid cloud cover definitions used here. The differences in spatial distribution between all clouds and liquid clouds again support the conclusion that ice clouds are a strong contributor to the large total cloud fractions in the south of Greenland.

Figure 10 shows the spatial distribution of interannual anomaly of liquid (Fig. 10b) and total cloud cover (Fig. 10a) during the period 2008-15. Here we use the relative liquid cloud cover definition. Years 2012 and 2010 are the most positive liquid cloud anomalies over the period. In most regions the liquid cloud cover remains close to the multiyear average $(+1 \%-2 \%)$. The largest enhancements in those years are mostly located in western Greenland, and particularly in the northwest around the NEEM station. The enhanced liquid cloud cover influences the total cloud cover, which is also very slightly higher $(+1 \%)$ in these years compared to the rest of the period (Fig. 10a). The years 2010 and 2012 correspond to well-documented maximum melt events over Greenland. In 2010, the persistence of warm temperatures from winter to summer induced a deficit of snowfall as well as a longer exposure of the bare ice on the surface to solar radiation (Tedesco et al. 2011). In our observations, the positive liquid cloud anomaly occurs west of $35^{\circ} \mathrm{W}$, which is consistent with a decrease in snowfall in this region, and possibly an increase in liquid precipitation. In 2012, 97\% of the surface melted on 1112 July, compared to $35 \%$ on average for the 1981-2010 period (Tedesco et al. 2013; Hall et al. 2013). As with 2010, 2012 was associated with persistent anticyclonic conditions in southern Greenland, which led to above average surface temperatures (Tedesco et al. 2013). In addition, warm and moist air was likely advected from the western subtropical North Atlantic Ocean through atmospheric river events (Neff et al. 2014; Bonne et al. 2015), which could help explain the positive liquid cloud cover anomaly detected over most of Greenland in CALIPSO observations. Those two years confirm that enhanced liquid cloud occurrence generally occurs simultaneously with warm air conditions above Greenland and enhanced ice sheet melt.

Figure 10a also shows that 2009 is the least cloudy year over the period from 2008 to 2015: the total cloud cover vestigate the interannual variability of Greenland clouds. The annual mean cloud cover differs significantly between

\section{Interannual variability in Greenland cloud covers}

Using almost $10 \mathrm{yr}$ of $C A L I P S O$-GOCCP data, we in-
FIG. 9. Spatial maps of the Greenland annual mean cloud cover (a) all clouds, (b) absolute liquid clouds only, and (c) relative liquid cloud cover only. The mean total or liquid cloud cover amounts are given in the title of each plot.






\section{a) CALIPSO total cloud cover inter-annual anomaly}


\section{b) CALIPSO liquid cloud cover anomaly}


FIG. 10. Interannual anomalies of the (a) total cloud cover and (b) liquid cloud cover over the 2008-15 time period from CALIPSOGOCCP. The annual mean over Greenland is given in the title of each plot. We computed the same maps with $\mathrm{CC}_{\text {liq,abs }}$ and found that the interannual variation and the geographical localization of the liquid cloud cover anomalies remain the same but on average the annual mean liquid cloud cover over all Greenland increased by $7.5 \% \pm 2.4 \%$ relative to $\mathrm{CC}_{\text {liq,rel }}$.

anomaly is strongly negative $(-8 \%)$ on average over the entire Greenland subcontinent. Despite this large deficit in total cloud cover in 2009 compared to the other years, the liquid cloud deficit is moderate ( $-1 \%$; Fig. 10b) and liquid clouds are more numerous along the east coast. This implies that the cloud deficit is mostly supported by a deficit in high-altitude ice clouds rather than in lowaltitude liquid clouds. Box et al. (2010) showed that 2009 had the lowest melt extent since 2001 and an abnormally cold mean surface temperature relative to the 2008-15 mean. This cold air mass temperature likely influenced the deficit of clouds observed by CALIPSO.

In summary, the interannual anomalies of the liquid and total cloud patterns during the time period $2008-15$ suggest that the observed negative total cloud cover anomalies can be significant $(-10 \%)$ and are primarily due to deficits of ice clouds (not liquid clouds) distributed homogeneously over the entire Greenland territory with no specific pattern. These anomalies are associated with cold air temperatures over Greenland and decreased ice sheet 
melt. Moreover, the observed positive liquid cloud cover anomalies are moderate $(+1 \%$ or $+2 \%)$; they mostly occur over east/central Greenland and are slightly more pronounced over the northeast. These anomalies are associated with warm air mass temperatures over Greenland and increased surface melting.

\section{Summary}

In this work, the CALIPSO-GOCCP cloud cover retrieved over Greenland was compared with ground-based lidar and radar observations collected at Summit, and with other satellite cloud amount datasets from the GEWEX cloud assessment. These comparisons showed that, on average over the year, CALIPSO-GOCCP had a lower total cloud cover $(-9.3 \%)$ and cloud fraction profile below $4 \mathrm{~km}$ AGL $(-17.4 \%$ if the cloud fraction profile in Fig. $6 \mathrm{~d}$ is vertically averaged from 0 to $4 \mathrm{~km}$ AGL in 2013) than ground-based observations. However, CALIPSO-GOCCP reported larger cloud cover than most of the GEWEX datasets $(+6.7 \%$ compared to the multisensor mean).

Differences between CALIPSO-GOCCP and the ground-based radar are likely driven by the cloud detection threshold used in CALIPSO-GOCCP. This threshold is defined to avoid false detection during daytime and cannot detect the optically thin (IWC $<$ $2.5 \times 10^{-3} \mathrm{~g} \mathrm{~m}^{-3}$ ) low-altitude ( $<4 \mathrm{~km} \mathrm{AGL)}$ ice clouds. We designed for this study an alternative version of the cloud detection algorithm that can more successfully detect such clouds. The associated dataset CALIPSO$\mathrm{GOCCP}_{\text {green }}$ included more false positive detections at higher altitudes when the sun was above the horizon. In July and August liquid clouds were responsible for the full attenuation in $50 \%$ of the lidar profiles and might have hidden clouds below $2 \mathrm{~km}$ AGL. Another way to improve the ice cloud detection without changing the SR threshold could be to horizontally average the profiles from 1 to $5 \mathrm{~km}$ along the satellite track to increase the SNR, as in the CALIPSO-ST product. However, this method degrades the horizontal resolution.

Liquid cloud cover amounts derived from CALIPSO and ground-based instruments are quite consistent for either cloud cover definition as defined in the CALIPSOGOCCP standard algorithm or using ground-based measurements. As a result, we concluded that CALIPSO is a good instrument to evaluate the liquid cloudiness over Greenland. In contrast, low-altitude optically thin ice clouds $(\tau<0.3)$, which are frequent over Greenland, are not well identified in the regular CALIPSO-GOCCP or by the ground-based lidar.

Space-based active remote sensing observations provide a new look at the temporal and spatial cloud variability over all of Greenland, and help put the Summit observations in perspective. The variability of total and liquid cloud cover at Summit is similar to northern Greenland $\left(>72^{\circ} \mathrm{N}\right)$ where the atmosphere is drier. Southern Greenland $\left(<72^{\circ} \mathrm{N}\right)$ is cloudy year round (cloud cover $=60 \%-70 \%$ ), largely because of the prominent presence of free-tropospheric ice clouds much of the time. These results imply that the cloud seasonal cycle in the north drives the total Greenland cloud annual variability with a maximum in summer.

CALIPSO-GOCCP also reports more low-level clouds $(<2 \mathrm{~km} \mathrm{AGL})$ at Summit, relative to other parts of Greenland, year round. In general the total cloud cover increases from northern to southern Greenland. Liquid clouds are common around the coasts, but there is also a marked increase in liquid clouds over central Greenland. The similar seasonal cycles and values of liquid-only cloud cover over all Greenland regions reveal that the environmental conditions have a minimal effect on the liquidonly cloud cover.

During the 2008-15 time period sampled by CALIPSO large occurrences of liquid clouds were associated with high surface melting twice in 2010 and 2012. This study did not document how the atmospheric circulation drives the formation of those clouds, but there is evidence to suggest that the clouds did play a role in the enhanced melt. More work is needed to understand the interactions among large-scale circulation, cloud formation, and surface melting over Greenland.

Acknowledgments. The authors thank the three anonymous reviewers for their useful comments that helped to improve the manuscript. They also wish to thank NASA, CNES, and Climserv for giving access to the CALIOP data. The Summit Station datasets and research were provided by the ICECAPS project supported by the U.S. National Science Foundation (PLR-1303879, PLR1314156, PLR-1304692, PLR-1314358), the U.S. Department of Energy Atmospheric Radiation Measurement Program, and the U.S. National Oceanic and Atmospheric Administration. Thanks to the GEWEX community for creating the various datasets as part of the Cloud Assessment exercise and making them available online. Thanks to Patrick Raberanto for providing the modified versions of CALIPSO-GOCCP used in this study. This work was supported in part by the CNES/EECLAT project.

\section{REFERENCES}

Bennartz, R., and Coauthors, 2013: July 2012 Greenland melt extent enhanced by low-level liquid clouds. Nature, 496, 83-86, doi:10.1038/nature12002.

Blanchard, Y., J. Pelon, E. W. Eloranta, K. P. Moran, J. Delanoë, and G. Sèze, 2014: A synergistic analysis of cloud cover 
and vertical distribution from A-Train and ground-based sensors over the high Arctic station Eureka from 2006 to 2010. J. Appl. Meteor. Climatol., 53, 2553-2570, doi:10.1175/ JAMC-D-14-0021.1.

Bonne, J.-L., and Coauthors, 2015: The summer 2012 Greenland heat wave: In situ and remote sensing observations of water vapor isotopic composition during an atmospheric river event. J. Geophys. Res. Atmos., 120, 2970-2989, doi:10.1002/2014JD022602.

Box, J. E., I. Bhattacharya, J. Cappelen, D. Decker, X. Fettweis, K. Jezek, T. Mote, M. Tedesco, 2010: Greenland [in "State of the Climate in 2009"']. Bull. Amer. Meteor. Soc., 91, S79-S82.

Cawkwell, F. G. L., and J. L. Bamber, 2002: The impact of cloud cover on the net radiation budget of the Greenland ice sheet. Ann. Glaciol., 34, 141-149.

Cesana, G., and H. Chepfer, 2013: Evaluation of the cloud thermodynamic phase in a climate model using CALIPSOGOCCP. J. Geophys. Res. Atmos., 118, 7922-7937, doi:10.1002/ jgrd.50376.

— J. E. Kay, H. Chepfer, J. M. English, and G. de Boer, 2012: Ubiquitous low-level liquid-containing Arctic clouds: New observations and climate model constraints from CALIPSOGOCCP. Geophys. Res. Lett., 39, L20804, doi:10.1029/ 2012GL053385.

_, and Coauthors, 2016: Using in situ airborne measurements to evaluate three cloud phase products derived from CALIPSO. J. Geophys. Res. Atmos., 121, 5788-5808, doi:10.1002/ 2015JD024334.

Chepfer, H., S. Bony, D. Winker, M. Chiriaco, J.-L. Dufresne, and G. Sèze, 2008: Use of CALIPSO lidar observations to evaluate the cloudiness simulated by a climate model. Geophys. Res. Lett., 35, L15704, doi:10.1029/2008GL034207.

,,--- , G. Cesana, J. L. Dufresne, P. Minnis, C. J. Stubenrauch, and S. Zeng, 2010: The GCM-Oriented CALIPSO Cloud Product (CALIPSO-GOCCP). J. Geophys. Res., 115, D00H16, doi:10.1029/2009JD012251.

— , G. Cesana, D. Winker, B. Getzewich, M. Vaughan, and Z. Liu, 2013: Comparison of two different cloud climatologies derived from CALIOP-attenuated backscattered measurements (level 1): The CALIPSO-ST and the CALIPSO-GOCCP. J. Atmos. Oceanic. Technol., 30, 725-744, doi:10.1175/JTECH-D-12-00057.1.

Church, J. A., and Coauthors, 2013: Sea level change. Climate Change 2013: The Physical Science Basis, T. F. Stocker et al., Eds., Cambridge University Press, 1137-1216.

English, J. M., J. E. Kay, A. Gettelman, X. Liu, Y. Wang, Y. Zhang, and H. Chepfer, 2014: Contributions of clouds, surface albedos, and mixed-phase ice nucleation schemes to Arctic radiation biases in CAM5. J. Climate, 27, 5174-5197, doi:10.1175/ JCLI-D-13-00608.1.

Fichefet, T., C. Poncin, H. Goosse, P. Huybrechts, I. Janssens, and H. Le Treut, 2003: Implications of changes in freshwater flux from the Greenland ice sheet for the climate of the 21st century. Geophys. Res. Lett., 30, 1911, doi:10.1029/ 2003GL017826.

Flynn, C. J., A. Mendoza, Y. Zheng, and S. Mathur, 2007: Novel polarization-sensitive micropulse lidar measurement technique. Opt. Express, 15, 2785-2790, doi:10.1364/OE.15.002785.

Griggs, J. A., and J. L. Bamber, 2008: Assessment of cloud cover characteristics in satellite datasets and reanalysis products for Greenland. J. Climate, 21, 1837-1849, doi:10.1175/ 2007JCLI1570.1.

Guzman, R., H. Chepfer, V. Noel, T. Vaillant de Guélis, J. E. Kay, P. Raberanto, G. Cesana, M. A. Vaughan, and D. M. Winker, 2017: Direct atmosphere opacity observations from CALIPSO provide new constraints on cloud-radiation interactions. J. Geophys. Res. Atmos., 122, 1066-1085, doi:10.1002/2016JD025946.

Hall, D. K., J. C. Comiso, N. E. DiGirolamo, C. A. Shuman, J. E. Box, and L. S. Koenig, 2013: Variability in the surface temperature and melt extent of the Greenland ice sheet from MODIS: Temperature and melt of Greenland ice. Geophys. Res. Lett., 40, 2114-2120, doi:10.1002/grl.50240.

Hu, Y., D. Winker, P. Yang, B. A. Baum, L. Poole, and L. Vann, 2001: Identification of cloud phase from PICASSO-CENA lidar depolarization: A multiple scattering sensitivity study. J. Quant. Spectrosc. Radiat. Transfer, 70, 569-579, doi:10.1016/ S0022-4073(01)00030-9.

Intrieri, J. M., M. D. Shupe, T. Uttal, and B. J. McCarty, 2002: An annual cycle of Arctic cloud characteristics observed by radar and lidar at SHEBA. J. Geophys. Res., 107, 8030, doi:10.1029/ 2000JC000423.

Kay, J. E., and A. Gettelman, 2009: Cloud influence on and response to seasonal Arctic sea ice loss. J. Geophys. Res., 114, D18204, doi:10.1029/2009JD011773.

- and T. L'Ecuyer, 2013: Observational constraints on Arctic Ocean clouds and radiative fluxes during the early 21 st century. J. Geophys. Res. Atmos., 118, 7219-7236, doi:10.1002/ jgrd.50489.

_ , L. Bourdages, N. B. Miller, A. Morrison, V. Yettella, H. Chepfer, and B. Eaton, 2016: Evaluating and improving cloud phase in the Community Atmosphere Model version 5 using spaceborne lidar observations. J. Geophys. Res. Atmos., 121, 4162-4176, doi:10.1002/2015JD024699.

Liu, Y., S. A. Ackerman, B. C. Maddux, J. R. Key, and R. A. Frey, 2010: Errors in cloud detection over the Arctic using a satellite imager and implications for observing feedback mechanisms. J. Climate, 23, 1894-1907, doi:10.1175/2009JCLI3386.1.

Marchand, R., G. G. Mace, T. Ackerman, and G. Stephens, 2008: Hydrometeor detection using CloudSat-An Earth-orbiting 94-GHz cloud radar. J. Atmos. Oceanic Technol., 25, 519-533, doi:10.1175/2007JTECHA1006.1.

Miller, N. B., M. D. Shupe, C. J. Cox, V. P. Walden, D. D. Turner, and K. Steffen, 2015: Cloud radiative forcing at Summit, Greenland. J. Climate, 28, 6267-6280, doi:10.1175/JCLI-D-15-0076.1.

Mioche, G., O. Jourdan, M. Ceccaldi, and J. Delanoë, 2015: Variability of mixed-phase clouds in the Arctic with a focus on the Svalbard region: A study based on spaceborne active remote sensing. Atmos. Chem. Phys., 15, 2445-2461, doi:10.5194/ acp-15-2445-2015.

Moran, K., B. Martner, M. Post, R. Kropfli, D. Welsh, and K. Widener, 1998: An unattended cloud-profiling radar for use in climate research. Bull. Amer. Meteor. Soc., 79, 443-455, doi:10.1175/1520-0477(1998)079<0443:AUCPRF>2.0.CO;2.

Morrison, H., G. de Boer, G. Feingold, J. Harrington, M. D. Shupe, and K. Sulia, 2012: Resilience of persistent Arctic mixed-phase clouds. Nat. Geosci., 5, 11-17, doi:10.1038/ngeo1332.

Nayak, M., and Coauthors, 2012: CloudSat anomaly recovery and operational lessons learned. Proc. 12th Intl. Conf. on Space Operations (SpaceOps), Stockholm, Sweden, International Committee on Technical Interchange for Space Mission Operations and Ground Data Systems, doi:10.2514/6.2012-1295798.

Neff, W., G. Compo, F. M. Ralph, and M. D. Shupe, 2014: Continental heat anomalies and the extreme melting of the Greenland ice surface in 2012 and 1889. J. Geophys. Res. Atmos., 119, 6520-6536, doi:10.1002/2014JD021470.

NGDC/NESDIS/NOAA/U.S. Department of Commerce, 1995: TerrainBase, Global 5 arc-minute ocean depth and land elevation from the U.S. National Geophysical Data Center 
(NGDC). Research Data Archive at the National Center for Atmospheric Research, Computational and Information Systems Laboratory. Accessed January 2014. [Available online at http://rda.ucar.edu/datasets/ds759.2/.]

Noel, V., and H. Chepfer, 2010: A global view of horizontally oriented crystals in ice clouds from Cloud-Aerosol Lidar and Infrared Pathfinder Satellite Observations (CALIPSO). J. Geophys. Res., 115, D00H23, doi:10.1029/2009JD012365.

Pincus, R., S. Platnick, S. A. Ackerman, R. S. Hemler, and R. J. P. Hofmann, 2012: Reconciling simulated and observed views of clouds: MODIS, ISCCP, and the limits of instrument simulators. J. Climate, 25, 4699-4720, doi:10.1175/JCLI-D-11-00267.1.

Reverdy, M., H. Chepfer, D. Donovan, V. Noel, G. Cesana, C. Hoareau, M. Chiriaco, and S. Bastin, 2015: An EarthCARE/ATLID simulator to evaluate cloud description in climate models. J. Geophys. Res. Atmos., 120, 11 090-11 113, doi:10.1002/2015JD023919.

Sassen, K., 1991: The polarization lidar technique for cloud research: A review and current assessment. Bull. Amer. Meteor. Soc., 72, 1848-1866, doi:10.1175/1520-0477(1991)072<1848: TPLTFC $>2.0 . \mathrm{CO} ; 2$.

Seo, E.-K., and G. Liu, 2005: Retrievals of cloud ice water path by combining ground cloud radar and satellite high-frequency microwave measurements near the ARM SGP site. J. Geophys. Res., 110, D14203, doi:10.1029/2004JD005727.

Shupe, M., 2011: Clouds at Arctic atmospheric observatories. Part II: Thermodynamic phase characteristics. J. Appl. Meteor. Climatol., 50, 645-661, doi:10.1175/2010JAMC2468.1.

— T. Tttal, S. Y. Matrosov, and A. S. Frisch, 2001: Cloud water contents and hydrometeor sizes during the FIRE Arctic Clouds Experiment. J. Geophys. Res., 106, 15 015-15 028, doi: 10.1029/ 2000JD900476.

— S. Matrosov, and T. Uttal, 2006: Arctic mixed-phase cloud properties derived from surface-based sensors at SHEBA. J. Atmos. Sci., 63, 697-711, doi:10.1175/JAS3659.1.

— , V. P. Walden, E. Eloranta, T. Uttal, J. R. Campbell, S. M. Starkweather, and M. Shiobara, 2011: Clouds at Arctic atmospheric observatories. Part I: Occurrence and macrophysical properties. J. Appl. Meteor. Climatol., 50, 626-644, doi:10.1175/2010JAMC2467.1.

—_ and Coauthors, 2013: High and dry: New observations of tropospheric and cloud properties above the Greenland Ice
Sheet. Bull. Amer. Meteor. Soc., 94, 169-186, doi:10.1175/ BAMS-D-11-00249.1.

Spinhirne, J. D., S. P. Palm, and W. D. Hart, 2005: Antarctica cloud cover for October 2003 from GLAS satellite lidar profiling. Geophys. Res. Lett., 32, L22S05, doi:10.1029/2005GL023782.

Stubenrauch, C. J., W. Rossow, and S. Kinne, 2012: Assessment of global cloud datasets from satellites. WCRP Rep. 23/2012, $175 \mathrm{pp}$.

— , and Coauthors, 2013: Assessment of global cloud datasets from satellites: Project and database initiated by the GEWEX radiation panel. Bull. Amer. Meteor. Soc., 94, 1031-1049, doi:10.1175/BAMS-D-12-00117.1.

Tedesco, M., X. Fettweis, M. R. van den Broeke, R. S. W. van de Wal, C. J. P. P. Smeets, W. J. van de Berg, M. C. Serreze, and J. E. Box, 2011: The role of albedo and accumulation in the 2010 melting record in Greenland. Environ. Res. Lett., 6, 014005, doi:10.1088/1748-9326/6/1/014005.

— — - T. Tote, J. Wahr, P. Alexander, J. E. Box, and B. Wouters, 2013: Evidence and analysis of 2012 Greenland records from spaceborne observations, a regional climate model and reanalysis data. Cryosphere, 7, 615-630, doi:10.5194/ tc-7-615-2013.

Thorsen, T. J., Q. Fu, J. M. Comstock, C. Sivaraman, M. A. Vaughan, D. M. Winker, and D. D. Turner, 2013: Macrophysical properties of tropical cirrus clouds from the CALIPSO satellite and from ground-based micropulse and Raman lidars. J. Geophys. Res., 118, 9209-9220, doi:10.1002/ jgrd.50691.

Van Tricht, K., and Coauthors, 2016: Clouds enhance Greenland ice sheet meltwater runoff. Nat. Commun., 7, 10266, doi:10.1038/ncomms10266.

Wang, X., and J. R. Key, 2005: Arctic surface, cloud, and radiation properties based on the AVHRR Polar Pathfinder dataset. Part I: Spatial and temporal characteristics. J. Climate, 18, 2558-2574, doi:10.1175/JCLI3438.1.

Wang, Z., and K. Sassen, 2001: Cloud type and macrophysical property retrieval using multiple remote sensors. J. Appl. Meteor., 40, 1665-1682, doi:10.1175/1520-0450(2001)040<1665: CTAMPR $>2.0 . \mathrm{CO} ; 2$

Winker, D. M., and Coauthors, 2010: The CALIPSO mission: A global 3D view of aerosols and cloud. Bull. Amer. Meteor. Soc., 91, 1211-1229, doi:10.1175/2010BAMS3009.1. 